\title{
ELECTRONIC CONTROL OF LOCAL UNIFORMITY OF ILLUMINANCE FROM POWER LED
}

\author{
Valentin LISOVENKO \\ https://orcid.org/0000-0002-4255-2589 \\ Kharkiv National University of Internal Affairs, \\ Kremenchuk flight college \\ Denys Valentynovych LISOVENKO \\ https://orcid.org/0000-0002-0006-8035 \\ Odessa Military Academy \\ Oleksandr BAZIK \\ https://orcid.org/0000-0003-4492-8081 \\ Yurii SHMELEV \\ https://orcid.org/0000-0002-3942-2003 \\ Kharkiv National University of Internal Affairs, \\ Kremenchuk flight college \\ Sławomir BYŁEŃ \\ slawomir.bylen@wat.edu.pl \\ https://orcid.org/0000-0002-4565-4388 \\ Military University of Technology \\ Faculty of Security, Logistics and Management \\ Institute of Logistics
}

Abstract: It has been suggested to assess non-uniformity of illuminance by the coordinate distribution of its gradient. By the example of mathematical model, the possibility to form a desired illuminance gradient profile from a multicomponent module by means of electronic control of the LED lighting parameters. Keywords: LED, multicomponent module, lighting unit, luminous intensity, lighting parameters 


\section{INTRODUCTION}

Sharing radiotechnical and lighted aids extends the functionality of navigation systems, improves safety during low visibility takeoff and landing of aircrafts. In the most critical stages of piloting an aircraft, the aerodrome lighting system is a reliable source of visual information. In connection with brisk development of pilotless aircraft worldwide, the components of aeronautical equipment operating in the infrared (IR) band of electromagnetic waves are particularly in-demand, as IR cameras, thermal imagers are an integral part of the payload of unmanned aerial vehicles. The current stage, the development of light signaling devices is focused on the use of solid-state semiconductor sources, which are more effective by many performance criteria in comparison with thermal radiation sources. Physical properties of semiconductor injection emission sources allow further improvement of airfield spotlights and markers (increase in lifetime, higher reliability, optimization of light distribution, etc.) via implementation of electronic control of lighting parameters.

\section{ANALYSIS OF PUBLICATIONS}

Over the past few years of the development of electronic instrument-making, the highest achievements are observed in the areas of optoelectronics and are associated with the development of high performance photodetectors, high-brightness LEDs and semiconductor lighting units of various designations (Gridin, Zaytsev, Ryzhikov, Shcherbakov, 2012). There occurs mass replacement of conventional light sources by semiconductor analogs. The introduction of LED (light-emitting diode) technology in the manufacture of airfield lighting equipment seems promising (Galakova, Lyalyutskaya, Galakova, 2016; Adakin, Irevlina, 2016; Zyryanov, Volkov, Dmitriyev, 2011; Holovenskyi, Lisovenko, 2017; Holovenskyi, 2018; Holovenskyi, Andrusevych, Lisovenko, 2017; Holovenskyi, Bazyk, Lisovenko, 2018; Thesis work; Lisovenko, 2006; Anisimov, Budak, Zhukov, Kaloshin, Shishkin, 2016). New epitaxial technologies for heterostructures type Al-In-Ga-P, In-Ga-N, Ga N allow achieving almost $100 \%$ internal quantum efficiency of luminescence in different optical bands of the emission spectrum. The result is that LEDs have higher energy efficiency today as compared with gas discharge fluorescent lamp, and their luminous efficiency is expected to increase to $150 \mathrm{~lm} / \mathrm{W}$ (Mills, 2003a; Mills, 2003b).

LED small size expands the range of geometric configurations for collecting them into modules, which in turn opens up possibilities for designing individual lighting technology models for special requirements that should be considered as early as at the model design stage. The objective is a general transition from manual calculations to computer modeling of the structural elements of individual LEDs and their modules, as well as their lighting characteristics. Calculations of parameters of the secondary optics and lighting characteristics of modules have been successfully developed for different 
layout configurations of LEDs in lighting modules for planes of different spatial orientation (Udaltsov, Uvarova, 2010; Gorbunova, Korotaev, Peretyagin, Cherotov, 2013; Peretyagin, 2015; Sobolev, Poddenezhny, 2011; Sobolev, Poddenezhny, 2011). The main idea is to simulate the synthesis of the physical parameters of individual components into the integral lighting characteristics of a general lighting unit. It is important to establish the lighting parameters patterns of the LED lighting unit depending on the characteristics of its components and the geometry of their spatial arrangement. LEDs are commonly point sources with a predetermined directional diagram of the luminous intensity. Luminous intensity diagrams can be conditionally classified into three types of mathematical approximations that are originally based on the Lambertian emitter diagram:

- as a $P$-times magnified polar angle $\theta-\cos (P \theta)$;

- as a power function with a different arithmetic nature of degree $m-\cos ^{\mathrm{m}}(\theta)$;

- as algebraic functions of $\cos \theta$.

The pressing matter is the search for the most successful mathematical approximations of the empirical curves of luminous intensity of LED modules with different LED arrangement configurations.

As for the airfield lighting equipment, the importance of expanding the functionality of on-line change in the light field characteristics at different stages of the aircraft take-off and landing should be noted. Regulation of the directional diagram of lighting devices is dictated by the variability of the flight situation, providing the most comfortable visual perception of the outside world by the crew. The directional diagram in modern aeronautical signal spotlights is static or changes by mechanical deformation of the emitting module membrane, on which LEDs are placed. This method of controlling the spotlight parameters has significant drawbacks $₫$ various kinds of aberrations, a rigid connection between the radiant intensity and beamwidth, low operational reliability, the need for high-accuracy deformation of the membrane in the form of quadric surfaces, which is a rather complex. Aberrations are partially eliminated by changing the structure of emission unit $\triangle$ placing the LED emission sources on flexible segments, lamels, which change their curvature from concave to convex under the action of the control mechanism, whereby the light distribution solid takes different forms of surfaces (Patent. LED spotlight with regulated emission indicatrix). However, the above-mentioned issues remain. Since modern LED manufacturing is robotic and high precision, the solution of these problems is possible provided complete rejection of a mechanical control of spotlight lighting parameters by replacing it to the electronic control.

\section{STUDY OBJECTIVE}

To theoretically investigate the possibility and conditions for the formation of the predetermined illuminance profile from the multicomponent LED spotlight by means of electronic control of LED lighting parameters. 
Basic material presentation

Let us consider a planar LED module with NLEDs with identically oriented principal optic axes and Cartesian coordinates $\left(x_{\mathrm{K}}, y_{\mathrm{K}}\right)$. Illumination from each of them on the plane perpendicular to the principal optic axes located at distance $z$ from the module (LEDs are taken as the point sources) is expressed by the inverse square law (Epstain, 1975):

$$
E_{\kappa}\left(\theta_{\kappa}, \varphi_{\kappa}\right)=\frac{I_{\kappa}\left(\theta_{\kappa}, \varphi_{\kappa}\right) \cdot \cos ^{3} \theta_{\kappa}}{z^{2}}
$$

where:

- $I_{\kappa}\left(\theta_{\kappa}, \varphi_{\kappa}\right)$ - luminous intensity of the $k$ LED;

- $\quad \theta_{K^{k}}, \varphi_{\kappa}-$ polar distance, longitude of spherical coordinates with pole at $k$ LED.

For the majority of LED body designs and secondary optics $I_{\kappa}$ does not depend on angle $\varphi_{\kappa}$, and the luminous intensity directional diagram can be represented as $I_{\kappa}\left(\theta_{\kappa}\right)=I_{o \kappa} \cdot \cos \left(P_{\kappa} \theta_{\kappa}\right)$. Then, expression (1) will have the form:

$$
E_{\kappa}\left(\theta_{\kappa}\right)=\frac{\cos \left(P_{\kappa} \cdot \theta_{\kappa}\right) \cos ^{3}\left(\theta_{\kappa}\right)}{z^{2}}
$$

where:

- $\theta_{\kappa}(x, y, z)=\arccos \left(\frac{z}{\sqrt{\left(x-x_{\kappa}\right)^{2}+\left(y-y_{\kappa}\right)^{2}+z^{2}}}\right)$;

- $\quad x, y, z$ - Cartesian coordinates of the point of observation;

- $I_{o \kappa}$ - luminous intensity of $k$ LED in direction $\theta_{\kappa}=0$;

- $P_{\kappa}=\frac{\pi}{3 \alpha_{\kappa}}$ - change factor parameter of $k$ LED directional diagram with respect to Lambertian emitter [20];

- $\quad \alpha_{\kappa}$ - half-width of the $k$ LED directional diagram.

The limiting value of argument $P_{\kappa} \theta_{\kappa}$ amounts to angle $\frac{\pi}{2}$. With known quantity $\alpha_{\kappa}$, which is presented in the LED nameplate data of with account of the ambiguity of function Arccos $\xi$, we have a range of $\theta_{\kappa}: \theta_{\kappa} \in\left[-\frac{3}{2} \alpha_{\kappa} ; \frac{3}{2} \alpha_{\kappa}\right]$.

As a result, the coordinate distribution of illuminance from the module in the plane under consideration takes the form:

$$
E_{z}\left(\theta_{\kappa}\right)=\frac{1}{z^{2}} \sum_{k=1}^{N} I_{o:} \cdot\left[H\left(\theta_{\kappa}+\frac{3}{2} \alpha_{\kappa}\right)-H\left(\theta_{\kappa}-\frac{3}{2} \alpha_{\kappa}\right)\right] \cdot \cos \left(\frac{\pi}{3 \alpha_{\kappa}} \cdot \theta_{\kappa}\right) \cdot \cos ^{3}\left(\theta_{\kappa}\right)
$$

where $\mathrm{H}(\theta)$ - asymmetric unit function (Heaviside). 
Visual evaluation of illumination non-uniformity of the working surface is subjective, and may be difficult under low intensity conditions. For objective evaluations, we can use numerical characteristics of the spread of values $E_{z}(x, y)$ relative to the mean: dispersion, standard deviation, coefficient of variation. In lighting engineering, the illumination profile control is estimated by the average to minimum illuminance area ratio $-E_{\text {aver }} / E_{\text {min }}$ (Knorring, Fadin, Sidorov, 1992). However, this ratio is not sufficiently integral to evaluate the illuminance non-uniformity between very close points of the surface.

Planar distribution $E_{z}(x, y)$ from the viewpoint of classical concepts is defined by distribution of the normal component of the Pointing vector and represents a stationary, planar, scalar field, the change of which in any fixed point $(x, y)$ can be characterized by a derivative in the chosen direction $\vec{l}$ or by illumination gradient. The gradient vector direction points to the maximum rate of increase $E_{z}(x, y)$ in any point of the surface. Planar distribution of the gradient module value:

$$
\left|\operatorname{grad}_{z}(x, y)\right|=\sqrt{\left(\frac{\partial E_{z}(x, y)}{\partial x}\right)^{2}+\left(\frac{\partial E_{z}(x, y)}{\partial y}\right)^{2}}
$$

characterizes the field of maximum rates of changes in illuminance and may be a local characteristic of the degree of illuminance non-uniformity. The plane sites or individual points $(x, y)$, where $\left|\operatorname{grad}_{z}(x, y)\right|=0$ correspond to mathematically uniform illuminance $E_{z}(x, y)=$ Const.

If coordinate $\mathrm{y}$ is presented as function of $\mathrm{x}$ in formulas (2), (3), (4), we can get distribution profiles $E_{z}(x)$ and $\left|\operatorname{grad} E_{z}(x)\right|$ on the curve of prespecified form $y=f(x)$. 


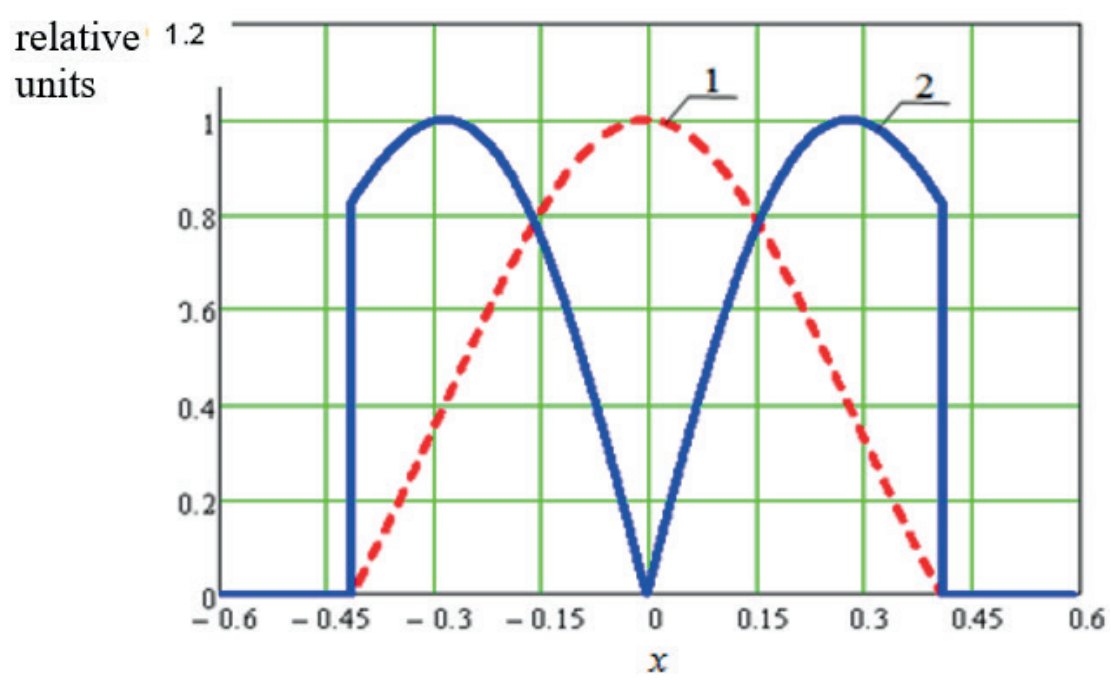

Fig. 1. Coordinate distribution of the illuminance normalized values

(curve 1) and plane illuminance gradient module (curve 2) from an isolated LED with parameters:

$$
x_{1}=0 ; y_{1}=0 ; I_{1}=1 ; \alpha_{1}=\frac{\pi}{12} ; z=1
$$

Source: Own elaboration

Figure 2 shows the illuminance distribution and the absolute value of its gradient in the plane which is at a distance $\mathrm{z}=3$ from the module consisting of 36 LEDs. The vector-matrices of the parameters, which are presented in the chosen system of physical quantities and take the form:

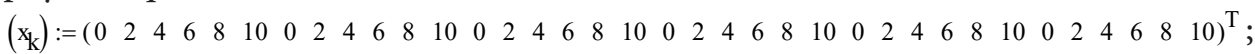

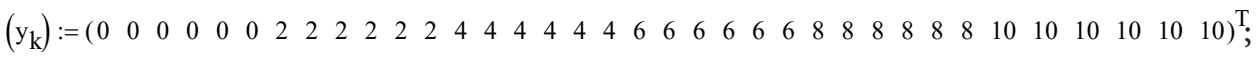

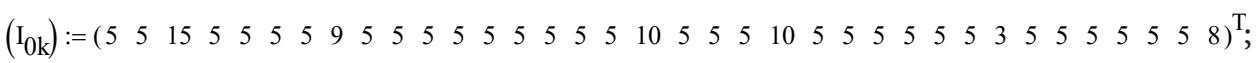

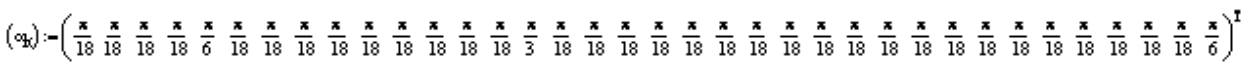

Figure 2 indicates that value $\left|\operatorname{gradE}_{z}(x, y)\right|$ is very sensitive to changes in illuminance. In practice, not visually registered non-uniformity of illuminance can be detected by registration of $\left|\operatorname{gradE}_{z}(x, y)\right|$, that is a large non-uniformity $\mathrm{E}_{z}(x)$ corresponds to the larger value in the vicinity of the point of interest. Registration of distributions $\mathrm{E}_{z}(x)$ and $\left|\operatorname{grad} E_{z}(x, y)\right|$ gives a fairly comprehensive information of the degree of illumination non-uniformity.

The above model makes it possible to analyze the effects of a single LED characteristics on the formation of the module lighting parameters. Independent control of each LED characteristics such as $\mathrm{I}_{\mathrm{OK}}, a_{\mathrm{K}}$ and their arrangement geometry produces 
the desired illuminance distribution profile. For circular symmetrical arrangement of the LEDs, it is more convenient to represent the LED coordinates in the polar coordinate system, then:

$\theta_{\kappa}\left(x, y, z, \rho_{\kappa}, \varphi_{\kappa}\right)=\operatorname{Arccos}\left(\frac{z}{\sqrt{x^{2}+y^{2}-2 \rho \kappa\left(x \cdot \cos \varphi_{\kappa}+y \cdot \sin \varphi_{\kappa}\right)+z^{2}+\rho_{\kappa}^{2}}}\right)$

where: $\rho_{\mathrm{K}^{\prime}} \varphi_{\mathrm{K}}$ - radius-vector and polar angle of $k$ LED, respectively.

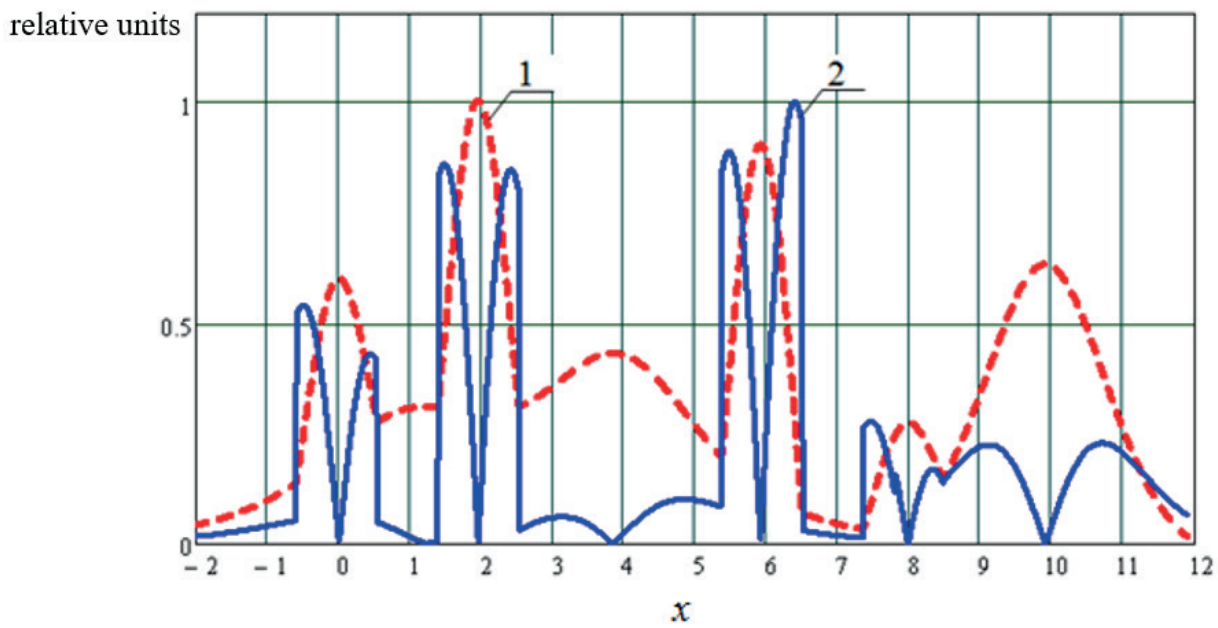

Fig. 2. Profiles distribution on diagonal $y(x)=x$ of the illuminated place: curve 1 - illuminance $E(x, y)$; curve 2 - illuminance gradient module $|\operatorname{grad} E(x, y)|$ Source: Own elaboration

Figure 3 shows the graphs of coordinate distributions of the site illuminance and illuminance gradient module for a spotlight of 25 LEDs arranged circularly symmetrically with polar coordinates:

$$
\begin{aligned}
& \left(\rho_{\mathrm{k}}\right):=\left(\begin{array}{lllllllllllllllllllllllll}
0 & 1 & 1 & 1 & 1 & 1 & 1 & 1 & 1 & 2 & 2 & 2 & 2 & 2 & 2 & 2 & 2 & 3 & 3 & 3 & 3 & 3 & 3 & 3 & 3
\end{array}\right)^{\mathrm{T}}
\end{aligned}
$$

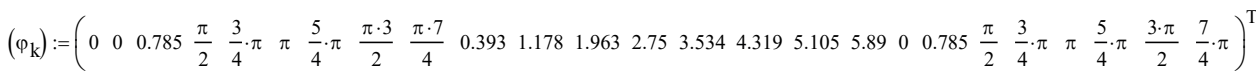

The photometric parameters $I_{\text {ок }}$ and $\alpha_{K}$ are artificially selected so as to obtain a square site with high illuminance uniformity:

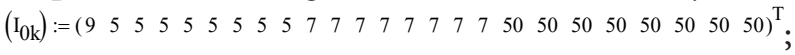

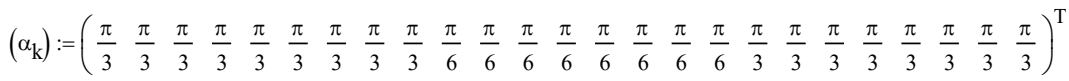


It is easily seen that in plane which is at a distance of $z=3$ from the LED module, there is a circular symmetrical site (radius $\sim 1$ ) with the most uniform illuminance; within its boundaries max $|\operatorname{gradE}(x, y)| \leq 0,1$, which is significantly less compared to other sites.

In practice, the plane illuminance distribution can be changed by switching individual groups of LEDs with different directional diagrams and specifically placed on the module. With a large number of LEDs, such electronic switching enable dynamic formation of the required set of the spotlight directional diagrams, which is an important need when used in lighting equipment (Holovenskyi, Lisovenko, Huliak, 2018; Holovenskyi, Lisovenko, 2017).

relative units

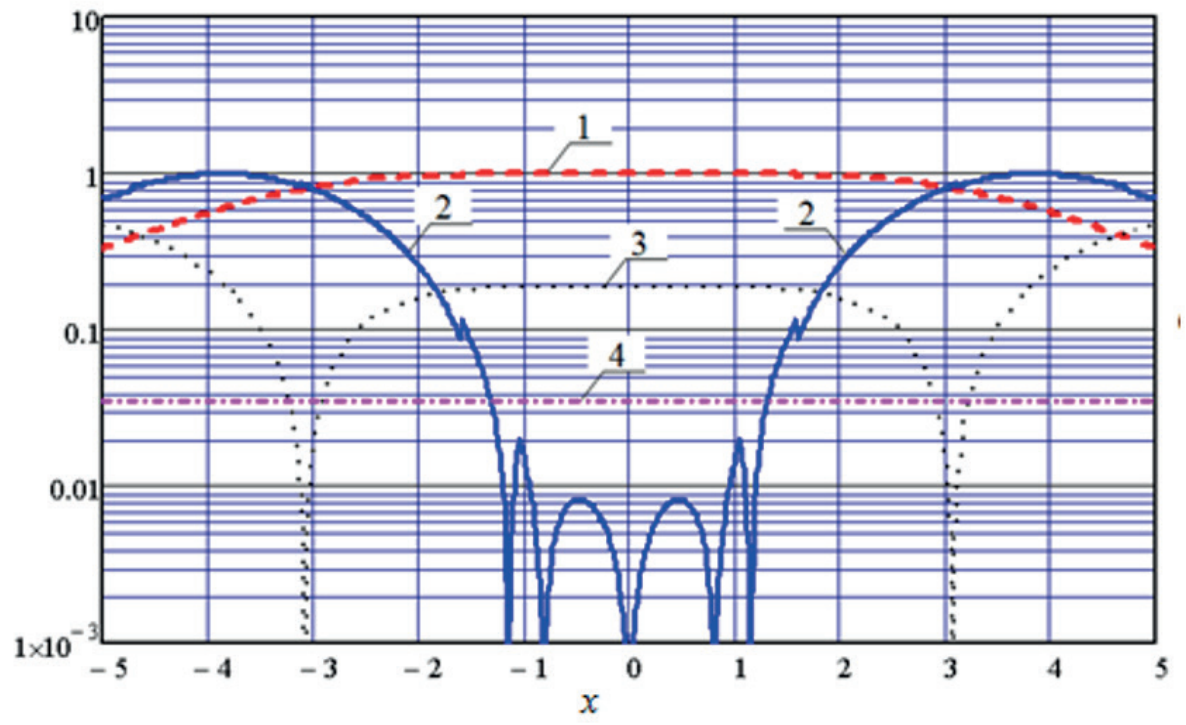

Fig. 3. Distribution profiles: curve 1 - illuminance; curve 2 - illumination gradient module; curve 3 quadratic deviation of illuminance from the mean value; curve 4 - illuminance dispersion Source: Own elaboration

The results obtained by the example of the LED model of multicomponent module are fully valid for module with semiconductor IR diode emitters. IR spotlights with electronically controlled focusing can be an important component of the payload of unmanned aircraft systems, and an additional means of aerial navigation in the form airfield based IR markers.

\section{CONCLUSIONS}

1. Plane illumination gradient and its module are highly sensitive characteristics of the plane illumination non-uniformity. 
2. The method for switching individual LEDs with different lighting parameters allows the synthesis of the directional diagram of the spotlight luminous intensity of the required configurations and achieving illumination of the predetermined characteristics of uniformity on the work surfaces.

3. If the algorithm base for transition from individual characteristics of LEDs to the parameters of the integrated module is available, it is possible to switch to the dynamic programmable electronic control of all lighting parameters of aeronautic spotlights and markers.

\section{REFERENCES}

[1] Gridin, V.N., Zaytsev, S.N., Ryzhikov, I.V., \& Shcherbakov, V.N. (2012). The development of the new generation semiconductor light sources. Kompyuternaya optika [Computer-based optics], No. 4, Vol. 36, 541-552.

[2] Galakova, G.A., Lyalyutskaya, M.Yu., \& Galakova, K.A. (2016). Innovation techniques in the production of aerodrome lighting equipment. Aktualnyye problemy aviatsii $i$ kosmonavtiki [Contemporary issues of aviation and astronautics], Vol. 2, 414-416.

[3] Adakin, V.A., \& Irevlina, P.S. (2016). The use of alternative light sources in low-intensity lights at flight strips. Inzhenero-tekhnicheskoye obespecheniye APK [Engineering support of the agrarian and industrial complex], Vol. 2, 3-7.

[4] Zyryanov, Yu.T., Volkov, V.V., Dmitriyev, V.M. (2011). Energy-saving technologies in the design and operation of lighting equipment complexes of airfields. Energosberezheniye $i$ energoeffektivnost [Energy saving and energy efficiency], No. 2 (38), 22-24.

[5] Holovenskyi, V.V., \& Lisovenko, D.V. (2017). Retrospective review, current stage and prospects for the use of LED emitters in light signaling devices. Odesa: Collection of scientific papers of the Military Academy. No. 2(8), 30-35.

[6] Holovenskyi, V.V. (2018). Extending the detection range of aerodrome beam signals in adverse meteorological conditions, Visnyk Natsionalnoho Aviatsiinoho Universytetu, [Bulletin of the National Aviation University]. Kyiv: National Aviation University, vol. 74, No. 1, 45-52.

[7] Holovenskyi, V.V., Andrusevych, A.O., \& Lisovenko, V.D. (2017). Light amplifiers, night vision cameras and thermal imaging systems in aviation. Aviation and Astronautics: Proceedings of the $7^{\text {th }}$ All-Ukrainian Research and Practical Conference, Kryvyi Rih. April 19, 2017. Ministry of Education and Science of Ukraine. State Higher Educational Institution Kryvyi Rih National University, 96.

[8] Holovenskyi, V.V., Bazyk, O.I., \& Lisovenko, V.D. (2018). Detection considerations for light and infrared signals of aerodrome spotlights. Kyiv: Collection of scientific papers of the Military Institute of Taras Shevchenko Kyiv National University. No. 4(61), 5-13.

[9] Thesis work. Lisovenko D.V. Rationale for the technical implementation of the light signaling system of the quick development flight strips based on LED emitters: Thesis work PhD: 20.02.14 - 2006 .

[10] Anisimov, V.I., Budak, V.P., Zhukov, V.V., Kaloshin, G.A., \& Shishkin, S.A. (2016). Visibility range of the signal LED lights. Svetotekhnika [Lighting Engineering], No. 4, 28-32.

[11] Mills, A., (2003), Nitridesin Nora-III-VS Review, Vol. 16, No. 6, pp. 34-38. 
[12] Mills, A. (2003), Solid stating light - a world of expanding opportunities at LED, 2002// III-VS Review, vol. 16, No. 1, pp. 30-33.

[13] Udaltsov, V.E., \& Uvarova, A. (2010). A Simulation of the emission spreading process in LEDs. Izvestiye vuzov. Priborostroyeniye [News of the Higher Educational Institutions. Instrument Making], Vol. 53. No. 7, 67-73.

[14] Gorbunova, E.V., Korotaev, V.V., Peretyagin, V.S., \& Cherotov, A.N. (2013). Simulation of the multicomponent emitting source. Izvestiye vuzov. Priborostroyeniye [News of the Higher Educational Institutions. Instrument Making], Vol. 56. No. 5, 31-34.

[15] Peretyagin, V.S. (2015). Research and development of multicomponent lighting devices for optical and electronic systems of the color analysis of objects: Thesis work PhD in Technical Sciences: 05.11.07. Saint Petersburg. 142.

[16] Sobolev, E.V., Poddenezhny, E.N. (2011). Simulation of the lighting characteristics of LED modules. Sovremennyye problemy svetotekhniki i eekertroenergetiki [Contemporary issues of lighting engineering and electric power engineering]. Proceedings of the $4^{\text {th }}$ International Research and Practical Conference of Kharkov National Academy of Municipal Economy. Kharkov. April 13-14, 81-83.

[17] Sobolev, E.V., Poddenezhny, E.N. (2011). Computer modeling of lighting elements of the LED lighting systems. Herald of P.O. Sukhoy Gomel State Technical University. 2011. No. 2 (45), 61-67.

[18] Patent. LED spotlight with regulated emission indicatrix. Patent number: 121853. Published: 12/26/2017 Authors: Holovenskyi V.V., Lisovenko D.V. International Patent Classification (IPC): F21K 9/65, F21W 111/043, F21K 9/00.

[19] Epstain, M.I. (1975). Optical radiation measurements in electronics. Energiya [Energy]. Moscow. 247.

[20] Titova, A.A. (2012). Experimental and numerical calculation of LED directional diagrams. Collection of scientific papers SWORLD. 2012. Vol. 7. No. 4, 10-16.

[21] Knorring, G.M., Fadin, I.M., Sidorov, V. N. (1992). Reference book for electric lighting design. Energoizdat. Saint Petersburg, 448.

[22] Holovenskyi, V.V., Lisovenko, D.V., \& Huliak, O.V. (2018). Method of light signals observation in the aircraft follow-up under adverse weather condition: patent No. 129019. Application date 09/01/2017, No. a 201708804. Published 10/25/2018. Bul. No. 20, 2.

[23] Holovenskyi, V.V., \& Lisovenko, D.V. (2017). LED spotlight with regulated emission indicatrix: patent No. 121.853. Application date 08/09/2017, No. a 201708256. Published 12/26/2017. Bul. No. 24, 4.

[24] LED spotlight with regulated emission indicatrix. Patent number: 121853., Published: 12/26/2017 Authors: Volodymyr Vasyliovych Holovenskyi, Denys Valentynovych Lisovenko International Patent Classification (IPC): F21K 9/65, F21W 111/043, F21K $9 / 00$. 